\title{
Ethical Health Technology Assessment in Latin America: Lessons from Canada and Argentina
}

\author{
Carolina Martin ${ }^{1}$, Bryn Williams-Jones ${ }^{2}$, María Graciela de Ortúzar ${ }^{3}$
}

\begin{abstract}
A wide array of biomedical and genetic technologies is becoming available in both developed and developing nations. This situation is the cause of growing concern for health policy makers who must evaluate the utility of these technologies for their inclusion in public health insurance programs. Ideally, policy makers would have the information necessary to rationally allocate scarce resources, prioritise technologies, and ensure fair access to necessary health care services. The reality, however, is that policy makers often do not have such information. In this paper, we argue that the field of Health Technology Assessment (HTA), through the integration of ethical analyses (i.e., an "ethical HTA"), can enable Argentinean and other Latin American policy makers to better understand the soco-ethical concerns raised by new biotechnologies.
\end{abstract}

Key words: health technology assessment, bioethics, policy, genetics, prenatal tests, Argentina, Canada

\section{Evaluación ética de la tecnología en salud de Latinoamérica: lecciones aprendidas de Canadá y Argentina}

Resumen: Una amplia gama de tecnologías biomédicas y genéticas ya se encuentra disponible tanto en los países desarrollados como en vías de desarrollo. De allí la importancia de evaluar dichas tecnologías para su ulterior inclusión en los programas de salud pública. Idealmente, los responsables de formular políticas dispondrían de la información necesaria para asignar los escasos recursos de manera racional, priorizar tecnologías y asegurar un acceso equitativo a los servicios de salud. Sin embargo, la realidad es que los responsables de formular políticas carecen a menudo de dicha información. En este trabajo argumentamos que la evaluación ética de tecnologías sanitarias permitiría a los decisores políticos argentinos y de otros países latinoamericanos comprender mejor las inquietudes socio-éticas que las nuevas biotecnologías plantean.

Palabras clave: evaluación tecnologías sanitarias, bioética, política, genética, pruebas prenatales, Argentina, Canadá

\section{Avaliação Ética da Tecnologia em Saúde na América Latina: Liçóes aprendidas do Canadá e Ar- gentina}

Resumo: Foi disponibilizada uma ampla coleção de tecnologias biomédicas e genéticas tanto em países desenvolvidos como nos países em desenvolvimento. Esta situação é a causa de preocupação crescente dos formuladores de políticas públicas de saúde sobre como avaliar a utilidade destas tecnologias para a sua inclusão em programas de saúde pública. Idealmente, os formuladores de políticas públicas deveriam ter a informação necessária para distribuir racionalmente os escassos recursos, priorizar tecnologias e garantir acesso justo aos serviços de cuidado à saúde necessários. A realidade, entretanto, é que os formuladores de políticas públicas em geral não têm tal informaçáo. Neste artigo, argumentamos que o campo da avaliação de tecnologia de saúde (ATS), através da integração de análise ética (ex., uma "ATS ética”), pode capacitar os formuladores de políticas públicas da Argentina e de outros países latino-americanos, a entender melhor as preocupaçóes sociais éticas producidas pelas novas biotecnologias.

Palavras-chave: avaliação de tecnologia em saúde, bioética, políticas públicas, genética, provas pré-natais, Argentina, Canadá

1 Ethics Consultant, Research Ethics Board, Centre Jeunesse de Montréal-Institut Universitaire, Montréal, Canada

2 Associate Professor, Bioethics Programs, Department of Social and Preventive Medicine, School of Public Health, Université de Montréal, Montréal, Canada

3 Associate Researcher at National Scientific and Technical Research Council -CONICET- Argentina

Correspondence: caromartinvar@yahoo.ca 


\section{Introduction}

The introduction of new biotechnologies in any health care system is a complex process that is closely tied to economic, political and cultural factors and thus poses a host of challenging social and ethical issues in need of urgent attention by policy makers. One approach that has been used (with some success) in developed countries to evaluate new and potentially contentious technologies for integration into health care systems, is the application of Health Technology Assessment (HTA) processes (1-3). HTA can be defined as "the scientific evaluation of medical technologies regarding their effectiveness, appropriateness, efficiency as well as social and ethical aspects and implications" (Swiss Network of HTA 2010)4. One of the aims of HTA is to provide the broad range of empirical and social information necessary for policy makers to make well founded decisions about the integration of new technologies into health programs.

In Latin America, and for our purposes Argentina, the production of HTA analyses is still quite limited. However, in March 2002, the Ministry of Health recognised the importance of HTA and announced that it would be necessary to implement a formal process of technology evaluation in order to help rationalise decisions about health care funding and delivery (República Argentina, Decreto no. 674/2003) $)^{5}$. In a context, such as Latin America, where poverty and social exclusion affect millions of people, the result is significant inequalities in access to health services and technologies. As such, HTA of new health technologies must be extended beyond cost-benefit analyses, to also include the evaluation of issues relating to fair and inclusive access to services, and the design of more just health and social policies. But producing an "ethical HTA" requires amongst other things (e.g., a clear framework and methodology, empirical evidence, capacity building and public policies) - knowledge and expertise in ethical analysis that is not often available in HTA agencies, in either developed or developing countries.

\footnotetext{
${ }^{4}$ For more information see the Swiss Network of HTA available at: http://www.snhta.ch/

${ }^{5}$ República Argentina. 2003. Resolución Ministerial no. 674/2003. Programa Médico Obligatorio y Evaluación de Tecnologías Sanitarias", edited by Superintendencia de seguros de la Nación. Buenos Aires: República Argentina (http://www.sssalud.gov.ar)
}

There are, however, some models of how ethics can be integrated into HTA processes. To illustrate key elements necessary for effectively integrating ethics and HTA in Argentina, we present the case of the Agence d'Évaluation de Technologies et de Modes d'Intervention en Santé (AETMIS) in Québec, Canada, as an example of how HTA agencies can work to more actively integrate ethical analyses into its HTA processes. Building on this example, we argue for the importance of conducting "ethical HTA" in Argentina that specifically includes considerations of equity, and focuses not simply on efficacy or efficiency. We further argue that local professionals trained in bioethics are legitimate and vital sources of advice on ethics matters, and can contribute both to the development of more fully informed HTA recommendations (e.g., about consequences of adopting a given technology), and to the development of greater public transparency in the policy arena.

\section{History \& Development of HTA}

Prior to the systematic use of HTA, policy makers lacked the technical knowledge and tools to analyse the consequences of implementing new technologies such as computerized tomography scanner, or diverse predictive or diagnostic tests(4). In 1974, the U.S. Senate requested the Office of Technology Assessment (OTA) to study the justifications for North American hospitals implementing expensive health technologies and procedures. The result of this inquiry was the production of a series of reports and the development of an innovative tool for the analysis of health policies(4). Since the 1980's, the interest manifested by different stakeholders (e.g., health care managers, the pharmaceutical industry, academics, patient associations, and policy-makers) for HTA has grown considerably, especially in the developed nations. The rapid deployment of new health technologies, their increasing costs in the context of limited health care budgets, and the uncertainty provoked by as yet unknown effects are just some of the reasons that have contributed to this interest in $\operatorname{HTA}(2,3,5)$.

\footnotetext{
${ }^{6}$ For a detailed discussion of the origins and development of HTA and the creation of the OTA, see for example the National Information Center on Health Services Research and Health Care Technology, available at: http://www.nlm.nih.gov/nichsr/hta101/ta10103.html
} 
By mid-1990, the USA, Canada and most western European countries had implemented diverse health technology evaluation systems through the creation of public and/or private agencies (e.g., ministerial commissions, non-governmental organisations, university research teams). These groups were given the mandate to evaluate the security, efficacy and cost-effectiveness of new biomedical technologies, but also to reflect on their economic, legal and socio-ethical implications; in practice, however, socio-ethical analysis has been and are still rarely performed(6).

International HTA groups were also created, most notably the International Society of Technology Assessment in Health Care (now called Health Technology Assessment International, HTAi) and the International Network of Agencies for Health Technology Assessment (INAHTA), established in 1993 and currently including members from more than 50 national HTA agencies.

Although the majority of HTA is performed in order to assess specific technologies, it can also be used as an approach to evaluate the performance of health care systems and services. For example, some Canadian provinces (notably Québec, Ontario and British Columbia) have implemented initiatives to reorganise services in order to respond more efficiently to their populations' health needs. In Canada, the restructuring of health care systems has in part been necessitated by the "aging population, rapid development of medical technologies and increasing costs” (7:1464).

In Latin America, however, HTA processes are much less well developed and HTA agencies are still few in number. In 1998, the Pan American Health Organization (PAHO) conducted a study with the aim of determining the situation of HTA in "the Americas". This study identified two major pitfalls for Latin American nations seeking to implement technology evaluation procedures: 1) the "misunderstanding" of decision-makers about the importance of HTA for the health care systems, and 2) the absence of specialised staff(2). This study also determined that, as a consequence of the lack of evaluations, countries in Latin America were incorporating new health technologies into their health care systems without taking into account their own regional particularities, giving as a result "a diffusion of sophisticated technologies" which are almost unrelated to the populations' needs(2).

In Argentina, until 2000, decision makers did not recognise HTA as a tool that could help with the rational allocation of resources (8). However following the severe economic crisis that affected the country in 2001, the demand for HTA has been growing considerably as well as its role in the decision-making process(9). Argentinean policy makers have noted that a formal process of technology evaluation can contribute to transparency and efficiency in health policy decision-making processes (República Argentina 2003). Decision makers are now more aware of the relevance of HTA and this encourage the development of local HTA processes(9).

In 2008, the Health Ministry created the Comisión Nacional Salud, Ciencia y Tecnologia (to replace the former Comiisón Nacional Salud Investiga) with, as one its aims, the institutionalization of HTA in the health care system and the promotion of scientific evidence in health policy decision making ${ }^{7}$. An HTA working group was created within this body in 2009; to date, the evaluations performed by consist primarily of literature reviews and consultation with experts, and the resulting short reports focus primarily on economic information, e.g., about cost-effectiveness. These technical reports, albeit very helpful, provide decision makers with only partial information about specific aspects of technologies, such as costs and efficacy, which is arguably insufficient to enable the development of comprehensive and effective health policies.

One point that deserves particular attention is the fact that technical reports usually lacks of formal recommendations about whether to include a technology in the health care system. Such recommendations would arguably not be possible (or at least not very helpful) if the primary analyses do not also integrate attention to social, ethical and political factors that go beyond issues of cost-effectiveness. The problem with such a

\footnotetext{
${ }^{7}$ See: República Argentina, Ministerio de Salud y Ambiente. Comisión Nacional Salud, Ciencia y Tecnología. Later, in 2009, the "Unidad Coordinadora de Evaluación y Ejecución de Tecnologías en Salud" was created within the Secretary of Policies, Regulations and Institutions by Ministerial Resolution 458.
} 
lack of formal recommendations is that it creates uncertainty and ambiguity for the various actors involved (e.g., patients, physicians, health managers, policy makers); without clear guidance, these actors will be hard pressed to make well informed decisions (e.g., about whether to use and/or pay for a procedure) in what are often very delicate situations.

The aforementioned awareness that decision makers currently show in Argentina about the important of HTA is a very positive step in the right direction. Yet as will be explained below, the systematised production of contextualised studies and formal integration of ethical issues in HTA is still missing in Argentina, as well as in the rest of the Latin American nations. Nevertheless, there is an opportunity for local HTA producers to broaden the scope of their evaluations. HTA is becoming both a professional practice and an academic discipline in some regional countries, such as Argentina (e.g., the work conducted by the IECS agency) ${ }^{8}$; and with a developing and vibrant bioethics community, there is also the possibility to integrate ethical expertise so as to build an ethical HTA that can help policy analyses and decision making, as is increasingly the case in North American and European nations.

\section{A Place for Ethics in Health Technology As- sessment?}

Following Blanquaert \& Caron(10) the process of HTA can be described as a combination of two phases: 1) assessment, which includes epidemiological studies, the collection of all available scientific information (e.g., literature review, cost-effectiveness analyses) and then a subsequent analysis and synthesis; and 2) appraisal, in which contextualised studies are conducted and recommendations made. As Blancquaert(11) explains, contextual analyses that are broader or more comprehensive than the standard or traditional assessments are needed in order to produce clear

\footnotetext{
${ }^{8}$ IECS is the only Argentinean institution (and one of only a few in Latin America) affiliated with the international network INAHTA. As such, the IECS is directly linked with the international HTA community, which facilitate the exchange of ideas, methodologies and reporting models that could be adapted to the local context. This relationship provides precious opportunities for collaboration and shared learning to help improve and enlarge the production of HTA in Argentina.
}

and pertinent recommendations adjusted to local realities. Specifically, appraisal takes into account the environment in which a technology emerges and the different positions of the various stakeholders concerned by the use of such a technol$\operatorname{ogy}(11)$.

Despite the recognition in the HTA community of the need for broader evaluations that include socio-ethical analyses, the aforementioned appraisal phase is not yet performed in a systematized manner by most HTA agencies. This gap between HTA mandate and practice has been highlighted by both HTA producers and bioethics scholars(6). Even when HTA producers recognise the importance of and need to address socio-ethical concerns, it has often proven difficult to conduct and integrate ethical analyses because of a lack of specialised staff and economic resources to assess, in a timely manner, all aspects of a technology $(12,13)$.

In addition, as noted by Lehoux and WilliamsJones(6), the absence of adequate frameworks and procedures to guide such ethical analyses further complicates the situation. As a result, the formal integration of socio-ethical analyses is mostly conducted by "ad-hoc" advisory groups (14), even in jurisdictions where HTA has been practiced for many years. It should not be surprising, then, that if integrating socio-ethical analyses into HTA is difficult in North American and Europe, the situation will be even more challenging in countries, such as those in Latin America, in which this multidisciplinary field of study is still in its earliest stages of development. Nonetheless, there are some models for integrating ethical analyses into HTA processes $(1,13,15,16)$ that are worth attention, and could be eventually adapted or modified to the different social contexts of Latin American countries.

\section{The Québec Experience: AETMIS}

One of the few HTA agencies in Canada that had attempted to integrate ethical analyses into its practices was the Agence d'évaluation des technologies et des modes d'intervention en santé (AETMIS), in the province of Québec. Created in 2000, AETMIS was an independent organi- 
sation linked to the Ministère de la santé et des services sociaux (MSSS, Ministry of Health and Social Services of Québec). The AETMIS recently merged with the Conseil du médicament (committee in charge of evaluating medications for inclusion in the Quebec public health insurance program), and in January 2011 became the Institut national d'excellence en santé et en services sociaux (INESSS); its future operating practices and the place for ethical analyses are as yet unknown, so for this paper we will focus on the practices of the AETMIS.

The goal of AETMIS was to support and counsel health decision makers in the Québec government in their development of health policy. AETMIS was strongly engaged in promoting evaluation, knowledge translation, teaching and other educational activities(17), similar to other HTA agencies in Canada and internationally. AETMIS performed comprehensive analyses (assessment and appraisal), that can include, for example, the use of statistics and other scientific or health information about the Québec population(11).

The ethical implications of a technology are analysed within Québec's socio-cultural, economic and political context. Different methods are employed to achieve this integration: for instance, focus groups may be organised with stakeholders or interviews conducted with different actors concerned by a given technology, depending on the particular circumstances of each evaluation. At this point, it is necessary to recognize the strong influence exerted by the various stakeholders involved in implementing such innovations in a given context (e.g., technology designers, health administrators, physicians, patient groups) as well as the existence of diverse perceptions, interests and expectations that each may have about the same technology. Considering these factors and integrating them as part of the HTA process allows the AETMIS evaluators to obtain more accurate information about the utility, feasibility and acceptability of a technology in the Québec context.

Each HTA report produced formulates pragmatic policy "recommendations directly applicable to the Québec health care system"(17). For example, in 2003, AETMIS produced a report about the use of prenatal screening for Down syndrome during the first-trimester. After evaluating diverse parameters, the report concluded that even while the screening modalities were effective, more research was still needed before implementing "wide-scale first-trimester screening in Québec"(18). In January 2009, the Québec Commissaire à la santé et au bien-être (MSSS) published a report that built on the AETMIS evaluation and, in light of new technological developments and changes in the social context, recommend the introduction of population screening for Down Syndrome. The important point to note is that in both cases, the social and ethical concerns related to Down Syndrome (e.g., issues of stigmatisation, access to services for a vulnerable population, equity in access to prenatal screening) where considered and integrated in the analyses and the broader policy making process.

The changes in medical practices engendered by the development of new biomedical technologies made it necessary for AETMIS to expand the traditional process of HTA to include assessment and appraisal processes; but they have also continued to examine and test different methods (e.g., working across diverse interest groups and stakeholders) with which to integrate ethics into HTA. To be clear, we are not suggesting that AETMIS is the ideal or perfect model for ethical HTA; instead, we argue that AETMIS is a helpful example or case study from which other agencies and countries can learn to support their own efforts to integrate ethics into HTA processes. To see how some of these lessons might be applied in the Argentinean context, we turn now to an examination of an ethical HTA for the case of prenatal genetic testing.

\section{An Ethical HTA in Argentina: The Example of Prenatal Genetics Testing}

To better illustrate the need to expand HTA processes in Argentina (and Latin America more generally) to include ethical analyses, we present here the case of prenatal genetic testing (PGT), a class of health technology that raises numerous social and ethical concerns that should be assessed, alongside clinical and economic considerations. 
In Argentina, the medical application for PGT in the public health care and social security system ${ }^{9}$ is still quite limited, nor are there well developed public policies or regulations governing the use of these technologies $(19,20)$. Nonetheless, private access to such services and other reproductive technologies is relatively easy (through private clinics) and Argentinean professionals employ the same techniques as their colleagues in developed countries $(20,21)^{10}$. This shows that there is at least some degree of acceptability of these technologies by the Argentinean public, and by health professionals.

Following Blancquaert et al.(22), we note that as objects of assessment, genetic or genomic technologies are very complex, raising a considerable number of concerns regarding appropriateness and acceptance of these new technologies in diverse societies. Although many socio-ethical concerns about PGT are shared by other branches of medicine (e.g., who will have access to the service, who will pay), some are particular to this technology, such as the right to reproductive autonomy, confidentiality of genetic information, and the potential risk of discrimination and stigmatisation. But PGT also raises questions about how to address diverging personal convictions, values and religious beliefs. In the specific case of Argentina, the lack of regulations or guidelines dealing with genetic tests in general has made possible the introduction of commercial PGT, some of which may lack medical validation $(20,23)$. All of these issues pose serious challenges for decision makers.

Probably one of the most important challenges for an effective HTA (to inform health care policies) in Argentina with regards to PGT —or for health services more generally- is the fragmentation of the health care system in terms of structure and organisation of insurance coverage (24). Even when HTA is conducted, the absence of formal recommendations following these assessments does not allow Argentinean policy makers to be fully informed about the range of contextual issues associated with a particular technology, and thus they remain unable to enhance the ef-

\footnotetext{
${ }^{9}$ The Argentinean health care system is formed by 3 subsystems: the public, the private, and the social security system.

${ }^{10}$ For a detailed list of genetic services and tests already available in Argentina, see for example Primagen Diagnósticos Genéticos available at: http://www.primagen.com.ar/diagnosticosprenatales.php
}

ficiency, the equity and quality and of the health policies. This situation is made worse by the fact that in Argentina, the links between the scientific and political spheres have been historically quite weak, which reduces the transparency of how policies are built. Regardless of the lack of regulatory oversight, Argentina, as with other neighbouring countries like Chile and Brazil, is rapidly incorporating new biomedical technologies such as molecular genetic tests (primarily into the private health sub-sector) that have been developed in North America and Europe (3,25); but this integration happens without appraisal of the social or political contexts relevant to their introduction. Such practices can result in a waste of limited resources, the use of possibly inappropriate technologies, and the perpetuation of a situation where populations have critical but unmet medical or public health needs; this creates inequity in access to important health care services and contributes to broader social injustice.

The tendency to adopt health technologies without detailed analysis is probably to some extent rooted in a widespread public belief in the power of high technologies to solve health problems (also maybe encouraged by the private healthcare sector), and a perception by many people (including policy makers and the general public) that access to these technologies is synonymous with being at the vanguard of modern medicine. As Lehoux(26) states, "for several observers, health technology...cannot be (irrationally) resisted", because "technology sounds modern... must be about the latest. It is also supposed to be better. But how and when do we know that an innovation is better?" (26:xii-3). The absence of contextualised assessments and integrated appraisals impedes efforts to determine if prenatal genetic tests or other biomedical technologies are appropriate or not for the Argentinean society.

To produce contextualised studies, it is obvious that substantial human and material resources are needed(7); but so to is awareness on the part of HTA producers of the importance of enlarging their studies beyond the analysis of clinical and economic considerations, to also include ethical and social issues, in order to make more accurate and pertinent recommendations. Unfortunately, chronic understaffing and a lack of sufficient fi- 
nancial resources at HTA agencies is a major part of the problem, although it can in some places be overcome by re-allocating local resources; more important, however, is to develop a willingness on the part of HTA agencies to engage in broader analyses.

In Argentina - as in other developing and developed countries - the government does not consider genetic testing (or most new reproductive technologies) as a priority for the public health care system(20); prenatal genetic tests are provided mostly by private institutions and thus are accessible only for the wealthiest. But there may be situations in which genetic tests are appropriate (e.g., for people belonging to certain at-risk groups) and justifiable in relation to other important health needs. Yet without a comprehensive HTA process that takes such issues into consideration, policy makers will be unable to rationally defend their choices (e.g., whether or not to include PGT in public health insurance).

We argue that important progress can be made if HTA producers in Argentina begin to integrate the aforementioned appraisal phase as a core part of their HTA processes. The capacity to conduct such appraisal will necessitate important efforts in education about the ethical issues related to health care and genetic technologies. HTA producers should, for example, reflect on and assess the possible consequences of not considering sensitive issues. For example, the growing commercialization of genetic tests can lead to an early introduction into the market of services that physicians may not yet be prepared to handle, and provide information to patients and third parties which can have serious legal consequences, such as discrimination, or even malpractice suits in the context of "wrongful life" claims(27) similarly strong patent protection and resulting high costs may mean that some genetic tests are simply too expensive to be considered for inclusion in public health insurance programs in countries like Argentina. It is also important to distinguish between those situations in which genetic tests are appropriate or needed (e.g., for people belonging to at-risk groups) and so justifiable in relation to other health needs; and those situations in which tests are introduced primarily because of commercial interest $(23,28)$.
In practice, integrating contextualised studies and ethical analysis into HTA processes will require, amongst others, the development of strategic partnerships between diverse spheres: academia, policy and practice $(11,29)$. In Argentina, a recent report from the aforementioned Comisión Nacional Salud, Ciencia y Tecnología(30) shows that those researchers working on human genetics and its clinical applications are disconnected from decisions about the provision of health services. Better collaboration with the medical genetics community is needed, as well as more fluid communication between practitioners and policy makers, to avoid any misunderstandings. For instance, in Argentina, the field of genetics is still closely associated in the public mind with eugenic practices, and this is arguably one of the principal reasons why PGT has not been included in public services $(19,30,31)$. Promoting education and dialogue among the different stakeholders -including patients and health professionalswould help enormously to eliminate such misperceptions and misinformation.

However, producing an ethical HTA requires at least some knowledge about bioethics, such as how to use and apply relevant ethical principles, theories of justice, or analytic frameworks. The issues faced by Argentinean HTA producers are very challenging, and arguably go beyond the tools that they currently have in hand. In the next section, we argue that Argentina's Bioethics community, which has developed substantially during the last decade, can contribute in important ways to the production of better and more ethical HTA.

\section{Building Local Capacity}

Although there have been some initiatives in Argentina to evaluate socio-ethical aspects raised by genetic and other biomedical technologies, this has tended to occur without formal integration into existing HTA processes. The aim of such ethical evaluations has been to examine the ethical, legal, and social issues (ELSI) of genetic technologies, as has already been done in other countries, most notably in the USA, Canada and in Western Europe. In Argentina, some National Universities — such as at the Universidad Nacion- 
al de La Plata (UNLP) and the Universidad de Buenos Aires (UBA $)^{11}$ - have begun developing bioethics centres and programs. For example, while the first ELSI courses for law and medical students were taught by invited international scholars, it is increasingly local bioethics scholars (many of whom received training abroad and participated in other ELSI courses offered in North America) who are now engaged in both research and teaching in Argentina ${ }^{12}$.

More recently, several research ethics bodies have been created in Argentina and begun participating in public and policy discussions about ethics and genetics, such as the Comision Nacional en Genética Humana created by the National Health Ministry; also, institutions such as the Observatorio de Bioética (created by the Facultad Latinoamericana de Ciencias Sociales, FLACSO) are analysing and discussing socio-ethical issues related to the use of new health technologies. Even though these bodies are not themselves HTA agencies, their work can be helpful for HTA producers. Nonetheless, the integration of ethics with HTA and the introduction of HTA into the policy sphere remain major challenges, and not only for developing countries $(32,33)$.

Progress can, however, be made if Argentinean HTA producers build links with institutions where technologies are analysed from an ethical and social perspective, as is the case with some public universities, ethics commissions and nongovernmental organisations. Another possibility is that HTA agencies could learn from the experience of AETMIS in Québec, and incorporate onto their staff scholars trained in bioethics in order to conduct their own analyses and reports. Such recruitment would be an opportunity for HTA staff to build awareness about ethics, and for bioethicists to recognise and better respond to the specific objectives and restrictions inherent in HTA processes (5).

\footnotetext{
${ }^{11}$ The UNESCO Bioethics Chair was established at the University of Buenos Aires (UBA) in 1994.

${ }^{12}$ The first ELSI course in Genetics, in 1998, was financed by the U.S. National Institute of Health and Dartmouth College, and directed by Prof. Ronald Green; this allowed Prof. M. Graciela de Ortúzar to start the first courses on these subjects in the Medicine and Law Faculty, in UNLP, CIF, and was followed by several research projects and doctoral theses.
}

Scholars trained in bioethics can contribute substantially to HTA processes. They can employ several approaches, both theoretical and empirical(6) and may be involved in conducting both qualitative and quantitative research to understand and measure what people feel or are concerned with, regarding a given technology. For instance, such research would be useful in building a better understanding of the experience of those people undergoing PGT in Argentina. By referring to ethical principles (e.g., autonomy, beneficence, justice) and identifying societal values (e.g., solidarity, empathy), ethical analyses can help to build relevant and practical frameworks to better analyse genetic technologies.

Such theoretical and empirical bioethics research can help to clarify a technology's social acceptability, appropriateness and utility within the Argentinean health care system. And when integrated with comprehensive HTA evaluations, it then becomes feasible to produce practical and relevant recommendations that can be used to make decisions on rational grounds, according to needs and not just according to particular interests or preferences. Yet, it is critical to be aware of and to guard against the use of rational bioethics-informed arguments in the service of non-transparent economic and/or political ends. For example, government actors may find such arguments useful for legitimising questionable practices, such as the mandatory or "strongly encouraged" implementation of new but possibly insufficiently tested or justified technologies (e.g., vaccines of $\mathrm{HPV}$ or $\mathrm{N} 1 \mathrm{H} 1$, or population genetic screening of newborns for conditions where there are no treatments) in order to "protect public health".

We agree with Battista and Hodge(29) that building (local) capacity and knowledge transfer mechanisms remain two major challenges for the progress of HTA in all countries. Nonetheless, local capacity building can be enhanced, for example, by encouraging and supporting existing academic activities, such as research in health services, policy and in public health(29). In the case of ethics expertise, it is important to recognise that bioethics research and education has grown considerably in Latin America since the 1990s(34-36). An opportunity exists, then, to 
bring together the bioethics, health research and HTA communities to discuss how to effectively integrate ethical reflection into HTA and policy making.

A promising strategy would be to start with a small scale pilot project at a public or private institution in which bioethicists are employed, to develop the aforementioned appraisal phase of the HTA process, for a particular health technology. For example, bioethics and social science scholars could help gather the necessary social and scientific information about PGT in Argentina, consult with key stakeholders (e.g., physicians working in hospitals in which PGT is provided, to document existing selection criterion, if any), conduct focus groups with patients in need of PGT to learn about their concerns, or survey genetics laboratories to learn what kinds of tests are in most demand. As seen in our example of AETMIS, the dissemination of study findings is an integral part of the HTA process; so in the context of the proposed pilot study, presenting research results in academic, public and policy forums could be a way to move the issue of PGT onto the political agenda in Argentina.

With regards to knowledge transfer, the communication and diffusion of HTA results and its translation into policy and practice needs to be enhanced in Argentina. As Battista and Hodge explain, these results are currently addressed almost exclusively to health ministers, but industry, clinicians and the public more generally should also be receptors of such information(29). Partnerships between a diversity of stakeholders are needed because such a translation is not just a "technical" or one-way (expert to user) procedure. Instead, evidence-based decision-making should be seen as an ongoing and interactive "social process" (32). Public participation in such social processes could be encouraged through the implementation of consultative mechanisms, as have been used by some European agencies (e.g., the "Publiforums" implemented by the Swiss Technology Assessment Agency). Such integration of citizens panels and other consultative mechanisms (e.g., roundtables) that facilitate discussions about the socio-ethical questions raised by new technologies $(6,37)$ would go some way towards reflecting the diversity of social values, and move beyond the strict epidemiological analyses in current HTA processes.

The creation of spaces that facilitate and encourage public participation is important, and some progress is already being made in Argentina. The so called "Argentinean Roundtable" is a public forum implemented by the National Ministry of Health, where different sectors of society (government, labour associations, scientific societies, the Catholic Church, etc.) participated in discussions about various health problems and their possible solutions(38). This sort of dialogue can also be stimulated by those in academia - an area that is strongly developed in Argentina - searching for new avenues of collaboration with governmental and private institutions.

\section{Conclusions}

In developing countries, people often experience numerous difficulties accessing health care services, especially for those people with the lowest income(39). In this context, more inclusive health policies which have the potential to improve access to essential services are necessary. To that end, we argue that HTA in Argentina, as well as in the rest of Latin America, must engage in a broader or contextualized assessment of new technologies, to include alongside assessment, the appraisal of socio-ethical aspects. In particular, there is real need to move beyond short technical HTA reports and to instead also formulate pragmatic and socially relevant policy recommendations.

There is arguably no single "best model" for how to integrate ethics into HTA, but it is certainly possible to learn from the successes and failures of other HTA producers. Primary research is still necessary in Argentina in order to clarify how socio-ethical questions should be appraised, and possible methods explored. An important first step should be building awareness on the part of HTA producers and decision makers about the importance of conducting comprehensive assessments. Such analyses can eventually contribute not only to more efficient technology integration (i.e., to produce the desired effect of improved public health), but also to a more efficient and equitable organisation of the health care system 
in Argentina (e.g., addressing the challenges of understaffing and chronic under-funding of genetic public facilities). It is essential to recognize that decisions based on expert analysis and advice can lead to better results(40), but for these results to be translated and accepted, they have to be integrated into broad public and policy discussions.

To address the complex social, ethical and economic challenges raised by new biomedical technologies such as PGT, the development and collaboration between interdisciplinary teams is needed. We have suggested that there is room for the participation of local bioethics scholars who have to date not been involved in HTA processes. These scholars can help to integrate the multiples perspectives of diverse stakeholders (e.g., publics, health professionals, corporate interests) in the appraisal process, and stimulate dialogue between the different actors; bioethics scholars could also be instrumental in helping HTA producers and decision makers think more reflexively about issues of fairness and equity when considering who should have access to PGT and other novel and costly health technologies. Without such an analysis, PGT will remain a hotly contested issue for the Argentinean public (and only accessible to the wealthiest) and an ongoing challenge for policy makers.
Social inequalities are one of the core problems in modern health care systems, both in the developed and developing countries. According to Lafortune et al., equity in health and health care requires the "realignment" of health policies, and for that, "a culture of evaluation needs to be infused" in the decision-making process(41:83). Progress to develop such a culture, can, we suggest, arise through the close collaboration of bioethics scholars and HTA producers, with the shared goal of aiming to construct ethical HTA that can guide policy-making in more reflexive, inclusive and transparent decision making.

\section{Acknowledgments}

Carolina Martin was supported by a Bioethics scholarship from the Faculty of Graduate Studies (Université de Montréal); Bryn Williams-Jones was supported by grants from the Social Sciences and Humanities Research Council of Canada (SSHRC Institutional pilot grant, 2007), and the International Institute of Research in Ethics and Biomedicine (IIREB travel award, 2008) and M. Graciela de Ortúzar was supported by National University of Patagonia Austral, Argentina (Project 29/C039, Director); National University of La Plata (Project 11 J098- Co-Director); National Scientific and Technical Research Council -CONICET(Associate Researcher), Argentina. 


\section{References}

1. Hofmann B. Toward a procedure for integrating moral issues in health technology assessment. International Journal of Technology Assessment in Health Care 2005b; 21(3): 312-318.

2. Pan American Health Organization. Developing Health Technology Assessment in Latin America and the Caribbean. Washington, D.C. 1998. Available from: http://www.paho.org/english/hsp/hsp-OP-115.htm (cited: January 22, 2010).

3. Valencia JE, Manrique RD. Evaluación de Tecnologías en Salud. Revista Ces Medicina 2004; 18(2): 81-86.

4. Lehoux P, Blume S. Technology assessment and the sociopolitics of health technologies. Journal of Health Politics, Policy and Law 2000; 25(6): 1083-1120.

5. Hofmann B. On value-judgements and ethics in health technology assessment. Poiesis \& Praxis: International Journal of Technology Assessment and Ethics of Science 2005a; 3(4): 277-295.

6. Lehoux P, Williams-Jones B. Mapping the integration of social and ethical issues in Health Technology Assessment. International Journal of Technology Assessment in Health Care 2007; 23(1): 9-16.

7. Battista RN, Hodge MJ. The evolving paradigm of health technology assessment: reflections for the millennium. Canadian Medical Association Journal 1999; 160(10): 1464-1467.

8. Rubinstein A, Belizán M, Discaciatti V. Has the Argentine financial crisis changed the minds of health decisionmakers? A qualitative study to explore the influence of health technology assessment (HTA) on resource allocation decision-making. First International Congress of HTA; 2004 May 30 - June 2; Krakow, Poland.

9. Pichon-Riviere A, Augustovski F, Rubinstein A. Health Technology Assessment in Argentina: six years in perspective. Proceedings of the 3rd Annual Meeting Health Technology Assessment International HTAi; 2006 July 2-5; Adelaide, Australia.

10. Blancquaert I, Caron L. Evaluation des technologies en génétique: Défis et opportunités. L'évaluation des technologies en génétique et le développement de politiques de santé au Canada, 2003, Sep. 11-12; Montreal, Canada

11. Blancquaert I. Managing partnerships and impact on decision-making: the example of health technology assessment in genetics. Community Genetics 2006; 9(1): 27-33.

12. Gallo P. Integrating ethical enquiry and health technology assessment: limits and opportunities for efficiency and equity. Poiesis \& Praxis: International Journal of Technology Assessment and Ethics of Science 2004; 2(2): 103117.

13. Van der Wilt GJ. Health technology assessment: trying to bring empirical and ethical inquiry together. Poiesis \& Praxis: International Journal of Technology Assessment and Ethics of Science 2004; 2(2): 195-206.

14. Faulkner A. Strange bedfellows' in the laboratory of the NHS? An analysis of the new science of health technology assessment in the United Kingdom. In Elston MA, (ed). The Sociology of Medical Science and Technology. Oxford: Blackwell; 1997: 183-207.

15. Burguess MM. Public consultation in ethics: an experiment in representative ethics. Journal Bioeth Inq 2003; 1: 4-13.

16. Heitman E. Ethical issues in health technology assessment. Conceptual categories and procedural considerations. International Journal of Technology Assessment in Health Care 1998; 13(3): 544-566.

17. AETMIS. Agence d'Évaluation de Technologies et de Modes d'Intervention en Santé. (Internet). Québec: AETMIS, About the Agency; 2010 Available from: http://www.aetmis.gouv.qc.ca/site/en_agence.phtml (cited: February 8, 2010).

18. AETMIS. Agence d'Évaluation de Technologies et Modes d'Intervention en Santé (Internet). Québec: Le dépistage prénatal du syndrome de Down et d'autres aneuplö̈dies au premier trimestre de la grossesse, 2003 Available from: http://www.aetmis.gouv.qc.ca/site/aid=503.phtml (cited: February 8, 2010).

19. Penchaszadeh VB. Argentina: Public Health Genomics. Public Health Genomics 2009; 12(1): 59-65.

20. Sommer SE. Estado actual de los tests genéticos en paises en desarrollo: el caso de América Latina y en especial de Argentina. Quimica Viva 2008; 7: 186-196.

21. Smith E, Martin C, Behrmann J, Williams-Jones B. Reproductive Tourism in Argentina: Accreditation and its Implications for Consumers and Policy Makers. Developing World Bioethics 2010; 2: 59-69.

22. Blancquaert I, Cleret de Langavant G, Bouchard L. L'évaluation des technologies de la santé à l'ère de la génomique. Le défi de la complexité. Ruptures, Revue Transdisciplinaire en Santé 2002; 9(1): 22-38.

23. De Ortúzar MG. El uso no médico de la información genética individual. En Bergel S. (editor). Genoma humano. Santa Fe: Rubinzal Culzoni; 2004: 283-299.

24. Rubinstein A, Pichon-Riviere A, Augustovski F. Development and Implementation of health technology 
assessment in Argentina: two steps forward and one step back. International Journal of Technology Assessment in Health Care 2009; 25(1): 206-209.

25. Zegers-Hochschild F. Attitudes towards reproduction in Latin America. Teachings from the use of modern reproductive technologies. Human Reproduction Update 1999; 5(1): 21-25.

26. Lehoux P. The Problem of Health Technology. Policy Implications for Modern Health Care Systems. New York; Routledge; 2006.

27. Miller F, et al. Predective genetic tests and health care costs: final report prepared for the Ontario Ministry of Health and Long Term Care, 2002 January 10.

28. Williams-Jones B, Burgess MM. Social contract theory and just decision-making: Lessons from genetic testing for the BRCA mutations. Kennedy Institute of Ethics Journal 2004; 14(2): 115-142.

29. Battista RN, Hodge MJ. The natural history of health technology assessment. International Journal of Technology Assessment in Health Care 2009; 25(1): 281-284.

30. República Argentina. Ministerio de Salud. Resolución Ministerial no 1522 (2008). Available from: http:// www.saludinvestiga.org.ar/institucional.asp. (cited: May, 2 2009)

31. Kaminker P. Mitos y Verdades en Genética Médica. Archivo Argentino de Pediatría 2006; 104(3): 246-252.

32. Battista RN. Expanding the scientific basis of health technology assessment: A research agenda for the next decade. International Journal of Technology Assessment in Health Care 2006; 22(3): 275-282.

33. Oliver A, Mossialos E, Robinson R. Health technology assessment and its influence on health-care priority setting. International Journal of Technology Assessment in Health Care 2004; 20(1): 1-10.

34. Lolas Stepke F. Bioethics at the Pan American Health Organisation: Origins, developments and Challenges. Acta Bioethica 2006; 12(1): 113-119.

35. Luna F. Bioethics and Vulnerability: A Latin American View. Amsterdam: Rodopi; 2006.

36. Salles A, Bertomeu MJ. Bioethics. Latin American Perspectives. Amsterdam: Rodopi. 2002.

37. Commissaire à la santé et au bien-être. Consultation sur les enjeux éthiques du dépistage prénatal de la trisomie 21, ou syndrome de Down, au Québec. Québec: Ministère de la santé et des services sociaux; 2009. Available from: http://www.csbe.gouv.qc.ca/fileadmin/www/RapportAvis/Trisomie21/CSBE_ RapportConsultationTrisomie21imprimable.pdf (cited: January 30, 2010).

38. Pan American Health Organization. Program on Organization and Management of Health Systems and Services Profile of the Health Services System. Argentina; 2002 ( $2^{\text {nd }}$ ed.): 28.

39. Peters DH, Garg A, Bloom G, Walker DG, Brieger WR, Rahman MH. Poverty and access to health care in developing countries. Annals of New York Academy of Sciences 2008; 1136: 161-171.

40. Rodemeyer M, Sarewitz D, Wilsdon J. Future of Technology Assessment. Woodrow Washington, DC: Wilson International Center for Scholars; 2005.

41. Lafortune L, Farand L, Mondou I, Sicotte C, Battista R. Assessing the performance of HTA Organizations: A Framework. International Journal of Technology Assessment in Health Care 2008; 24(1) 76-86.

Recibido: 25 de mayo de 2011

Aceptado: 12 de julio de 2011 